\title{
Experimental Study of Micro Mill-Grinding Process on Al 6061-T6
}

$$
\text { Jun Cheng }{ }^{1, a} \text {,Yadong Gong }{ }^{1, b} \text {, Yueming Liu }{ }^{1, c} \text { Jianyu Yang }^{1, d} \text {, }
$$

${ }^{1}$ School of Mechanical Engineering and Automation, Northeastern University, Shenyang, China

ajcheng@mail.neu.edu.cn, ' gongyd@mail.neu.edu.cn, 'liuyueming1000@163.com jyyang@mail.neu.edu.cn,

Keywords: Tool fabrication, Micro mill-grinding, Experimental study

\begin{abstract}
This paper presents a novel micro machining process that micro mill-grinding by combining micro-grinding and micro-milling. The principle of micro mill-grinding has been analyzed and a experiment is designed to study the influences in micro mill-grinding process on Al 6061-T6. The manufacturing is carried out on a desktop micro machine developed by NEU. In this research, analysis from results could found that the surface quality influences in micro mill-grinding is complicated affected both by milling and grinding, and conclude aspects such as cutter diameter, feed rate and material properties.
\end{abstract}

\section{Introduction}

Micromachining is a very useful processing method and it has been carried out to satisfy the demand for micro parts and micro structured elements which is growing fast $[1,2]$. Such micro products are applied widely to in many fields and industries[3], including telecommunications, portable consumer electronics, defense and biomedical engineering, and these micro-parts and structures are required to develop and fabricate low-cost tools which are micro-sized and have increased wear resistance[4]. Micro-milling operation is suitable for accomplishing a micro scale structure, but it also causes several problem such as surface defects, poor edge finish, comparatively large burrs and it is only ductile materials can be machined[5].

Recent years, micro cutting especially micro-milling have develop rapidly in related research about micro mechanical processing technology, but the surface quality of the micro cutting has not very ideal. Given the good quality of surface grinding, it adopts a new type of machining, Micro milling-grinding process. It not only overcomes the defects of larger surface roughness in micro-milling process, but also overcomes the insufficient of lower material removal rate in micro-grinding process.

This study is an attempted and exploratory research concerning micro milling-grinding process, and it focuses on micro milling-grinding mechanism, factors affecting the machined surface quality and the practical process, the comparison to the micro-milling.

\section{Analysis of Micro Mill-grinding process}

Tool fabrication. Micro milling is a widely used method of micro machining, in machining process it would cause several problems such as edge burr and surface elastic recovery. Micro grinding could solve problems caused in process of micro milling but it has a low manufacturing efficiency.

Micro mill-grinding as a novel micro machining method combining milling and grinding has been presented and the tool has been fabricated as Fig.1 shows. Grains has been coated on the rear face of micro milling cutter, during the machining process, the cutter could cut materials by milling first, then the grains on rear face of the cutter could grinding the finished surface. 


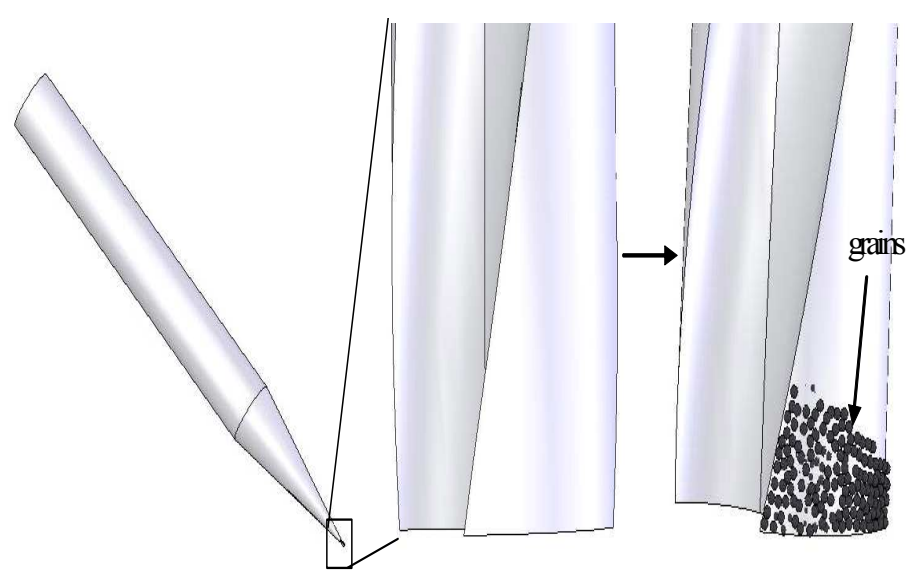

Fig. 1. Fabrication of micro mill-grinding cutter

This machining method has a high machining efficiency because it has a first step material cutting by mill cutter. Better surface quality is also be accomplished when the surface grinded by grains on cutter's rear face. The micro mill-grinding cutter in experiment in this paper is showed in Fig.2.

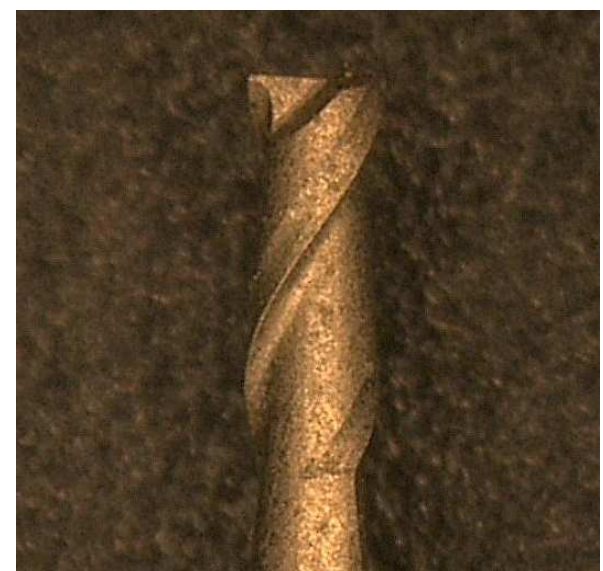

Fig. 2. Micro mill-grinding cutter in experiment

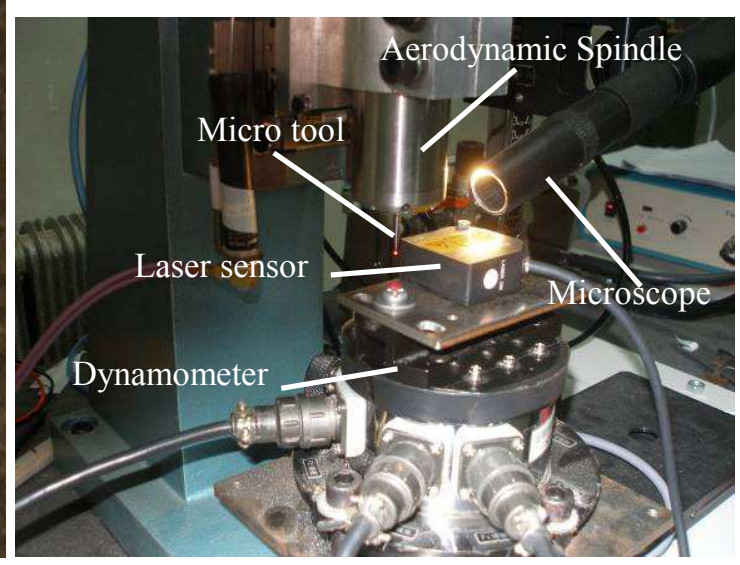

Fig. 3. Micro desktop machine

Experiment Equipment. Micro-machining experimental bench developed by northeastern university has been chosen for the experiment in this paper, which is shown as Fig.3, its aerodynamic spindle's rotation speed range is between $120,000 \mathrm{rpm}$ and $160,000 \mathrm{rpm}$, micro mill-grinding cutter which manufactured by coated grains has been developed as micro mill-grinding tool. Parameters of micro mill-grinding experiment are shown as Table 1.

In order to compare the surface quality in micro-scale, machining by micro-milling cutter of $700 \mu \mathrm{m}$ and $900 \mu \mathrm{m}$ diameter has been done first on AL 6061-T6's surface in this paper, surface quality of different parameters can be compared.

Table 1 Parameters of micro mill-grinding

\begin{tabular}{ccccc}
\hline$v_{s}(\mathrm{~m} / \mathrm{s})$ & $v_{w}(\mu \mathrm{m} / \mathrm{s})$ & $d_{s}(\mu \mathrm{m})$ & Work piece material & Tool's particle size \\
\hline 4.5 & 5 & $500 / 700 / 900$ & Al 6061-T6 & $1200 \#$
\end{tabular}

\section{Experimental Evaluation}

Experiment Results. Micro-machining experiment results of different parameter has been analyzed and the effects caused by several aspects on machining surface during the process of micro grinding also been investigated. 
Table 2 Surface roughness of different diameters

\begin{tabular}{cccc}
\hline Work piece material & particle size & $\mathrm{d}_{\mathrm{s}}(\mu \mathrm{m})$ & $\mathrm{Ra}(\mu \mathrm{m})$ \\
\hline \multirow{2}{*}{ A16061-T6 } & & 900 & 0.548 \\
& F1200 & 700 & 0.642 \\
& & 500 & 0.739 \\
\hline
\end{tabular}

It could be concluded that surface roughness increase with the micro mill-grinding cutter's diameter be smaller. $R_{a}$ of surface machined by $900 \mu \mathrm{m}$ diameter cutter is $0.548 \mu \mathrm{m}$.Cutting linear speed is $5.652 \mathrm{~m} / \mathrm{s}, 4.396 \mathrm{~m} / \mathrm{s}, 3.14 \mathrm{~m} / \mathrm{s}$ when cutter's diameter is $900 \mu \mathrm{m}, 700 \mu \mathrm{m}, 500 \mu \mathrm{m}$. And the cutting linear speed also be reduced by smaller cutter's diameter, time between two adjacent grains' cutting be longer, efficient grinding grains and surface quality would be corresponding low.

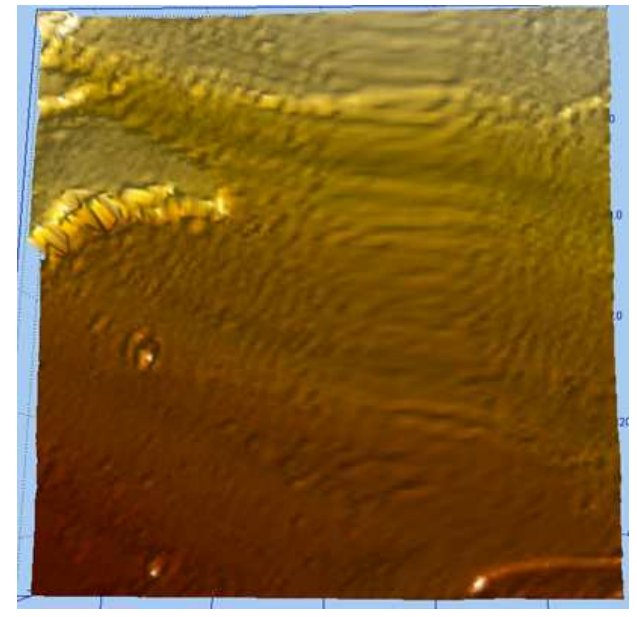

(a) $0.9 \mathrm{~mm}(100 \times 100 \mu \mathrm{m})$

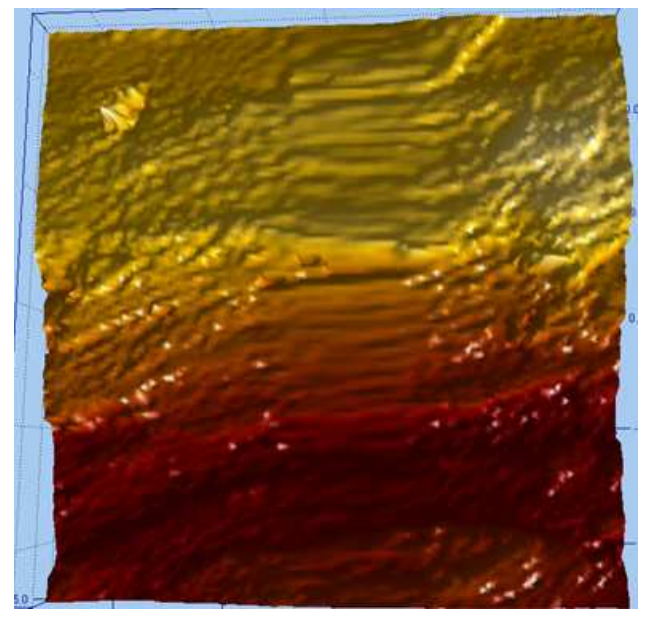

(b) $0.7 \mathrm{~mm}(100 \times 100 \mu \mathrm{m})$

Fig. 4. Surface skeleton maps of different diameters

The microcosmic surface of work piece after micro mill-grinding is showed in Fig.4, the microcosmic surface of different cutter diameters could been seen, surface accomplished by cutter of $0.9 \mathrm{~mm}$ diameter has a better surface quality compare with $0.7 \mathrm{~mm}$. Surface of $0.7 \mathrm{~mm}$ in Fig.4 (b) has several groves, these must be caused by low grinding speed.

Grits Shedding Analysis. In Micro-machining experiment results, a phenomenon was seen that with decreased grinding speed, cutting force of single abrasive particle is increasing and lead to the grits shedding from substrate. Fig.5 shows the shedding grits on machining surface of work piece with Al6061-T6 material.

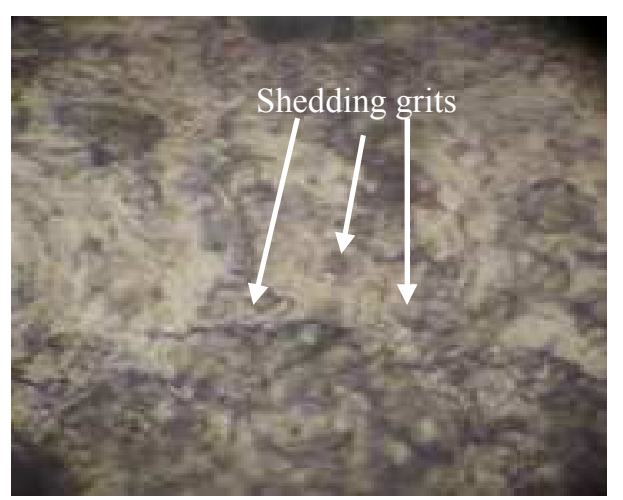

Fig. 5. Grits shedding on the machining surface 


\section{Conclusion}

A micro mill-grinding experiment on $\mathrm{Al}$ 6061-T6 is presented in this study for investigating the micro mill-grinding principle. A novel micro mill-grinding tool is fabricated by coating grains on the rear face of micro milling cutter. The manufacturing is carried out on a micro desktop machine developed by NEU. The roughness of AISI 1020 steel accomplished in the experiment is about $0.086 \mu \mathrm{m}$.

Influences caused by different cutters' diameter on surface quality are analyzed in this study, it has been tested that low surface roughness could be achieved on $900 \mu \mathrm{m}$ diameter of micro mill-grinding tool. A phenomenon of the grains shedding and its causing effects is discussed in this study.

\section{Acknowledgment}

The authors would like to thank the support of No. 51075064 by National Natural Science, and Foundation of China and Program for Changjiang Scholars and Innovative Research Team in University under Grant No IRT0816.

\section{References}

[1] Dornfeld D, Min S, Takeuchi Y (2006) Recent Advances in Mechanical Micromachining. Annals of the CIRP 55/2:745-768.

[2] Ohmori H, Katahhira K, Naruse T, Uehara Y, Nakko A, Mizutani M (2007) Microscopic Grinding Effects on Fabrication of Ultra-fine Micro Tools. Annals of the CIRP 56/1:569-572.

[3] Jinsheng Wang ,Yadong Gong, Gabriel Abba, Jean Francois Antoine, Jiashun Shi. Chip formation analysis in micromilling operation. International journal of advanced manufacturing technology, 2009; 45 (5-6): 430

[4] Shun-Tong Chena,*, Ming-Yi Tsai b, Yun-Cheng Lai a, Ching-Chang Liua. Development of a micro diamond grinding tool by compound process. Journal of Materials Processing Technology 209 (2009) 4698-4703

[5] J.C. Aurich, J. Engmann, G.M. Schueler, R. Haberland. Micro grinding tool for manufacture of complex structures in brittle materials Original Research Article. CIRP Annals - Manufacturing Technology, Volume 58, Issue 1, 2009, Pages 311-314.

[6] Y.D. Gong, J.S.Wang, G. Abba, J-F. Antoine, J.S. Shi. Tool Tip Trajectories Investigation and Its Influences in Micromilling Operation [J]. IEEE Review on Advances in Micro, Nano and Molecular Systems.

[7] Patrick, J. Heaney, Anirudha, V. Sumant and Christopher, D.Torres.Diamond coating for micro end mills: Enabling the dry machining of aluminum at the micro-scale[J], Diamond \& Related Materials, 2008, vol 17: pp 223-233. 